\title{
Spatial Monitoring of Pyrethroid Residues by RP-HPLC in Raw Bovine Milk in West Delta Region of Egypt
}

\author{
Amer Abd El-Moamen Amr* and Abou-Alella Abd-Elmohsen Sarah \\ Department of Food Hygiene and Control, Faculty of Veterinary Medicine, Alexandria University, Egypt. \\ *Corresponding author's Email: amramer@alexu.edu.eg; (DoRCiD: https://orcid.org/0000-0002-5495-5828
}

\begin{abstract}
The massive implementation of pesticides in agronomy, public health series, manufacturing, and production can increase pesticides in the environment leading to tremendous effects on human health. Hence, the current study aimed to evaluate the concentration and frequency of pyrethroid residues in raw bovine milk sourced from local producers at West Delta of Egypt carefully chosen from three cities on High-Performance Liquid Chromatography system. A total of 200 of raw bovine milk samples (Alexandria 75, El- Behera 75, and Matrouh 50) were analyzed. The achieved results indicated that Cypermethrin, Cyhalothrin, and Deltamethrin residues were respectively screened at frequencies of $18.66 \%, 17.33 \%$, and $14.66 \%$ in Alexandria, $21.33 \%, 17.33 \%$, and 16\% in El- Behera, and $44 \%, 28 \%$, and $24 \%$ in Matrouh. Cypermethrin was detected in a mean concentration level of 6.63, 5.98, and 10.74 in Alexandria, El- Behera, and Matrouh, respectively. However, Cyhalothrin and Deltamethrin had lower mean values of 4.66 and 2.45 in Alexandria, 5.14 and 3.05 in El- Behera, and finally 2.84 and 2.69 in Matrouh. There was no $\alpha$-Cypermethrin in all the investigated samples while Cypermethrin was present with the highest mean concentration and frequency levels in Matrouh, compared to other cities. Concerning the compatibility of examined samples with maximum residue levels (MRLs) set by the European Commission and Codex regulation, indicated only $2.66 \%, 1.33 \%$, and $0.00 \%$ for Cyhalothrin, and $1.33 \%, 4 \%$, and $2 \%$ for Deltamethrin examined samples in Alexandria, El- Behera, and Matrouh cities exceeded MRLs, respectively. As for Cypermethrin, its concentrations did not exceed MRLs. These results indicated a significant amount of these chemical pollutants in raw bovine milk offered by local producers in the West Delta of Egypt, which can threaten human life. Accordingly, continual assessment of pyrethroid residues in milk is of utmost importance to guarantee Egyptian consumers' health.
\end{abstract}

Keywords: Bovine milk, Cyhalothrin, Cypermethrin, Deltamethrin, MRLs, Pesticides, Pyrethroids, RP-HPLC

\section{INTRODUCTION}

Milk is crucial for human nutrition because it contains a plethora of indispensable compounds especially fat and proteins. Recently, many authorized organizations around the world are effectively acting on how to protect the food supply chain from being contaminated by forbidden hazards, such as pesticide residues in order to save human life. Pyrethroids are known as artificial insect repellents which originated from natural biopesticides called pyrethrin complexes which were extracted from a flowering plant named tanacetum cinerariifolium (Gammon et al., 2019). The most prevalent pyrethroids are bifenthrin, deltamethrin, cyfluthrin, cypermethrin, esfenvalerate, cyhalothrin, and permethrin (Gong, 2013). The environmental applications of pyrethroid insecticides include spraying around homes to control flies and ants (Feo et al., 2010), agricultural practices in crop protection against pests (Panseri et al., 2013), medical practices in topical control of lice and scabies and vector-borne diseases such as malaria which transmitted by mosquitoes, and veterinary practices in sprays, pour-on preparations and animal dipping (Corcellas et al., 2014).

Accidently, pyrethroids can get entrance to milk through unrestrained and haphazard use of these repellents for dairy animals or their surroundings such as foodstuffs, crops, contaminated drinking water, contaminated soil, and direct application to the bovine's body for controlling vector-borne diseases and parasites. Generally, the fatty portion of milk acts as an ideal solvent for most pyrethroids due to their lipophilic nature (Ismail and Elkassas, 2016). Although pyrethroids have great effectiveness, safety, high eco-friendly properties, low toxicity, relative stability, lower environmental persistence and selective insecticidal activity when matched with the natural pyrethrins, their extensive implementation has resulted in environmental pollution of ecosystems. In this regard, pyrethroids can either be easily hydrolyzed in the environment for few weeks or continue for more than one year based on some factors such as pyrethroid type, unmannerly usage, dampness, light and oxidation. In general, they are non-persistent contaminants and less hazardous when compared with organochlorine and organophosphorus compounds (Yu et al., 2017). Pyrethroids have hydrophobic and lipophilic characteristics, therefore unremitting consumption of contaminated milk with pyrethroids for long time can cause bio-accumulation of these residues in fatty tissues, in addition to their spreading in other body tissues via blood stream. Although, in most circumstances, pyrethroids can be hydrolyzed to detoxified 
metabolites, which generally have low and or non-toxic effects on animals and human, concerns about their tumor causing and endocrine troublesome should be in consideration (Bordoni et al., 2019). Degradable metabolites of pyrethroids such as 1-Cyhalothrin, $\alpha$-Cypermethrin and 3-phenoxybenzoic acid can be detected in animal or human secretions including milk (Wu et al., 2013).

On the other hand, chronic toxicity, carcinogenicity, genetic aberrations, endocrine-unsettlement and improper hormonal functions can be developed in some human bodies (Kampire et al., 2011). Chronic toxicity associated with many symptom complaints like vertigo, headache, vomiting, eye irritation, exhaustion, muscular convulsions and nervous symptoms. Chronic exposure to Cypermethrin has been reported to cause immune system toxicity or dysfunctionality (Wu et al., 2011). Moreover, there are few symptoms may be developed due to acute toxicity like skin itching, gastric, respiratory, convulsions and neurological disorders. Lately, cypermethrin has been reported to cause chronic neurotoxicity and tumors in brain especially in children or reproductive toxicity even at very low doses (Hudson et al., 2014). Moreover, Cypermethrin, has been classified by US Environmental Protection Agency (EPA) as potential carcinogenic agent while, Cyhalothrin was included in the list of group D carcinogens (IARC, 2014).

Globally, licenses about safety guides, corrective usage and withdrawal times of many pesticides have been established such as maximum residue levels (MRLs), for pesticides in foods of animal origin as well as plant products, stated by the European Union (EU) 37/2010 (European Commission, 2010) and the Codex Alimentarius Commission. In this regard, regulation (EC) 37/2010 has established MRL's for Cypermethrin (20 ppb), Deltamethrin (20 ppb) and Cyhalothrin (50 ppb). Furthermore, the Codex Alimentareous recommendations about the upper legal limits of Deltamethrin and Cypermethrin isomers in milk were 100 and 30 ppb, respectively (CAC, 2018). Therefore, the core-tip of the present research based on detection of selected three pyrethroid pesticides (Cypermethrin and its isomer ( $\alpha$ Cypermethrin), Cyhalothrin and Deltamethrin) in raw bovine milk samples collected from local producers at West Delta region of Egypt using High Performance Liquid Chromatography (HPLC). Finally, the detected contamination levels of these pesticides residues were compared with maximum residue levels and in turn this study will be useful for overall community and farmers that use pesticides with caution.

\section{MATERIALS AND METHODS}

\section{Materials \\ Milk collection}

Two hundred samples of fresh raw bovine milk, $250 \mathrm{ml}$ in polyethylene bag, were collected randomly from local producers from three cities (Alexandria 75, El- Behera 75 and Matrouh 50) in West Delta, Egypt. Samples were obtained as sold to the public and transferred as soon as possible in an icebox at $4 \pm 1^{\circ} \mathrm{C}$ to the laboratory with a minimum of delay.

\section{Chemicals and reagents}

Synthetic Pyrethroid Cyhalothrin 95\% and Deltamethrin 98\%, Cypermethrin and $\alpha$ - Cypermethrin 93\% were purchased from Tedia Company (Fairfield, OH, USA).

\section{Methods}

\section{Preparation of standard solutions for pyrethroid pesticides}

A typical stock solution was made separately for each type of pyrethroid pesticide in a concentration of $600 \mathrm{ppm}$ by liquefying $60 \mathrm{mg}$ of each pyrethroid with acetonitrile as a solvent then adding to $100 \mathrm{ml}$ of this solvent. From this stock standard solution, the pyrethroids working standard solutions were prepared by diluting separately $0.0625,0.125,0.250$, 0.500 and $1.0 \mathrm{ml}$ of the pyrethroids stock solution to $50 \mathrm{ml}$ with acetonitrile to obtain solutions of $0.75,1.5,3.0,6.0$ and $12.0 \mathrm{ppm}$, respectively. Such working standard solutions were prepared for each pyrethroid pesticide to determine the linearity of standard curve. All used solvents were HPLC grade.

\section{Determination of pyrethroid pesticides}

Sample fortification technique. The quantity of each pyrethroid was analyzed using the method of recuperation by fortification of the samples. The fortification was applied by adding standard concentration solutions to obtain different concentrations of pyrethroids in the samples. These fortifications were done separately for each examined pyrethroids. Calibration curves were constructed with fortified samples.

Extraction and purification technique. Accurately, $10 \mathrm{ml}$ of the sample were put in an Erlenmeyer flask and acidified with $1 \mathrm{~N} \mathrm{HCl}$ to approximately $\mathrm{pH} 4$. Further, $50 \mathrm{ml}$ acetonitrile were added and the flask was closed and vigorously shaken for 30 minutes. The sample was filtered in a glass funnel by Wattman filter paper NO.42 and the filtrate was collected in a beaker. The residue in the filter paper was transferred to the same Erlenmeyer flask, $25 \mathrm{ml}$ acetonitrile was added, and the flask was sealed and mechanically shaken for 15 minutes. Thus, the sample was filtered again using the same procedure and the same filter paper. The filtered sample was also collected in the same flask with the first filtrate. 


\section{Partitioning}

The filtrate (acetonitrile phase) in the beaker was transferred to a separator funnel and $15 \mathrm{ml} \mathrm{n}$-hexan were added and shaken for 1 minute. This procedure was repeated twice and acetonitrile phases were collected in the beaker while the hexanic phase was discarded. However, $45 \mathrm{ml}$ of the acetonitrile phase was added and shaken for approximately 1 minute. Finally, the acetonitrile layer was collected in a beaker containing the first acetonitrile phases and evaporated in an exhaustion system under stream of nitrogen as well as heated to dryness at $30^{\circ} \mathrm{C}$.

Column Chromatography Cleanup. In this step, dry residue was liquefied in $10 \mathrm{ml}$ n-hexan then elution was performed via a $4 \mathrm{~g}$ silica gel column. The silica gel was previously treated by hot air at $130^{\circ} \mathrm{C}$ for 5 hours and cooled then diluted with $5 \mathrm{ml}$ deionized water. The silica gel was put in the chromatographic column and eluted with $1 \mathrm{ml} \mathrm{n}$ hexan: diethyl ether (9: 1). The dry residue was diluted with 10ml $\mathrm{n}$-hexan and $7 \mathrm{ml} \mathrm{n}$-hexan: diethyl ether (9: 1). The eluate was dried at room temperature in an exhaustion system. The diethyl ether was purified before its use to eliminate the possible peroxides.

$\boldsymbol{R P}$-HPLC analysis. Actually, the dry residue was re-suspended with $1 \mathrm{ml}$ high grade acetonitrile, homogenized in a shaker for few seconds. Accordingly, the homogenate was injected onto High Performance Liquid Chromatography (HPLC). The suitable conditions of HPLC were: HPLC apparatus (Agilent1100) equipped with diode array detector (DAD); Column: Zorbex SBC 18 (150mm x 4.6mm x 0.5um film thickness); Mobile phase: acetonitrile: distilled deionized water (80: 20); Flow rate: $1.0 \mathrm{ml} / \mathrm{min}$.; Detector: $226 \mathrm{~nm}$ ultraviolet. Firstly, the homogenate was filtered in the sample filtering system of HPLC. After filtration, the mobile phase used in HPLC was acetonitrile: distilled deionized water (80: 20) under isocratic conditions and a flow rate of $1.0 \mathrm{ml} / \mathrm{min}$ and the mobile phase was filtered in the solvent filtering system.

Quantitative analysis. A comparison was performed between the injections of pyrethroid residues in the examined samples and other injections obtained by the standard solutions. Quantitative determination of these residues was obtained by the measurement of the peak areas in the chromatogram. Recovery rate $(\%)$ of pyrethroids pesticides in the examined milk samples were Cyhalothrin $91.9 \%$ and Deltamethrin $97 \%$, Cypermethrin $91 \%$ and $\alpha$ - Cypermethrin $93 \%$

\section{Data analysis}

The statistical data analysis of pyrethroid pesticides levels and frequencies in milk samples was exposed to techniques for analysis of variance (ANOVA), two-way test of variance in SPSS (Version 16). Subsequently, KruskalWallis test was used for conducting a nonparametric comparison including all milk samples among cities while, the comparison based on frequencies (\%) of detection which was evaluated by Fisher's Exact test.

\section{RESULTS}

The present results revealed the existence of selected pyrethroid residues (Cypermethrin, $\alpha$ - Cypermethrin, Cyhalothrin and Deltamethrin) in raw bovine milk samples collected from local producers in West Delta area of Egypt as follows: 75 milk samples collected from Alexandria city and 75 from El- Behera city and finally, 50 samples collected from Matrouh city. All milk samples were examined for detection the presence of selected pyrethroid residues. The data in Table 1 explained that all analyzed milk samples were polluted with selected pyrethroid residues at the maximum rates of detection except $\alpha$-Cypermethrin which was failed to be detected in all examined samples. In contrast, all selected pyrethroid residues were unnoticeable at the minimum detection values in examined milk samples. The most repeatedlynoticed pyrethroid residues were of Cypermethrin at the mean concentration levels \pm (standard deviations) of $6.63 \pm$ (16.54) and $5.98 \pm(15.05) \mathrm{ppb}$ among all collected milk samples from Alexandria and El- Behera cities, respectively with the highest level reported in Matrouh- collected milk samples which was $10.74 \pm(20.79)$ ppb of whole milk. By comparing the levels of contamination detection for all examined milk samples, there was a significant difference $(\mathrm{P} 1=$ 0.059) among the selected three cities. The percentages of contamination were detected in 18.66 and $21.33 \%$ of the collected milk samples from Alexandria and El- Behera, correspondingly with the highest percent of contaminated samples reported in Matrouh which was $44 \%$.

Although all contaminated milk samples by Cypermethrin were not exceed the MRL (100 ppb) according to CAC (2018), the frequencies of contamination among contaminated samples were significantly varied $(\mathrm{P} 2=0.032)$. In this regard, the mean contamination values \pm (standard deviations) and median levels (Q1-Q3) for contaminated samples were $34.57 \pm(21.79)$ and 29.15 (17.14 - 53.0) for Alexandria- contaminated milk samples while, the values among ElBehera- polluted milk samples were 26.91土 (16.07) and 36.30 (20.52 - 51.0). Finally, for Matrouh- contaminated samples, the values were $36.63 \pm(23.01)$ and 30.55 (15.25 - 52.02), respectively. The magnitude of Cyhalothrin detection levels showed clear differences among selected cities with the mean concentration levels \pm (standard deviations) in the following order: $5.14 \pm(12.62)>4.66 \pm(12.09)>2.84 \pm(6.42)$ for El- Behera > Alexandria > Matrouh- collected milk samples, respectively. 
Table 1. Levels and frequency of detection of selected Pyrethroids pesticides in raw bovine milk samples collected from local producers in West Delta, Egypt

\begin{tabular}{|c|c|c|c|c|c|c|c|c|c|}
\hline Insecticide (ppb) & Governorate & \multicolumn{4}{|c|}{ All samples } & \multicolumn{4}{|c|}{ Contaminated samples } \\
\hline \multirow{3}{*}{ Cypermethrin } & Alexandria & 75 & nd -75.61 & $6.63(16.54)$ & $0(0-0)$ & $14(18.66)$ & $0(0.0)$ & $34.57(21.79)$ & $29.15(17.14-53.0)$ \\
\hline & Matrouh & 50 & nd -84.11 & $10.74(20.79)$ & $0(0-13.51)$ & $22(44)$ & $0(0.0)$ & $36.63(23.01)$ & $30.55(15.25-52.02)$ \\
\hline & $\mathrm{P} 1=0.059, \mathrm{P} 2$ & 032 & & & & & & & \\
\hline \multirow{2}{*}{ Cyhalothrin } & Alexandria & 75 & $\mathrm{nd}-71.32$ & $4.66(12.09)$ & $0(0-0)$ & $13(17.33)$ & $2(2.66)$ & $26.88(15.97)$ & $21.34(15.76-36.07)$ \\
\hline & $\mathrm{P} 1=0.056, \mathrm{P} 2$ & 783 & & & & & & & \\
\hline \multirow{4}{*}{ Deltamethrin } & Alexandria & 75 & $\mathrm{nd}-37.65$ & $2.45(6.68)$ & $0(0-0)$ & $11(14.66)$ & $1(1.33)$ & $16.31(8.53)$ & $13.95(11.14-17.53)$ \\
\hline & El- Behera & 75 & nd -39.26 & $3.05(7.84)$ & $0(0-0)$ & $12(16)$ & $3(4.0)$ & $18.83(9.18)$ & $14.80(12.40-25.57)$ \\
\hline & Matrouh & 50 & nd -38.64 & $2.69(6.08)$ & $0(0-0)$ & $12(24)$ & $1(2.0)$ & $16.83(7.22)$ & $15.41(13.16-17.64)$ \\
\hline & $\mathrm{P} 1=0.112, \mathrm{P} 2$ & 02 & & & & & & & \\
\hline
\end{tabular}

\section{a-Cybermethrin was failed to be detected in all examined raw milk samples}

Min - Max: minimum - maximum; Q1: 25th percentile, Q3: 75th percentile; MRL: Maximum Residue Level as per the European Commission (EC) Regulation No 37/2010 (EU) for Cyhalothrin: 50 ppb, and (CAC, 2018) for Cybermethrin: 100ppb, $\alpha$ - Cybermethrin: 100ppb; Deltamethrin, 30ppb, SD: Standard Deviation; nd: non-detectable. P1 = Probability values result from the nonparametric comparison among cities (Kruskal-Wallis test) including all samples. P2 = Probability values result from the comparison among frequencies (\%) of detection (Fisher's Exact test). 
Moreover, when the rates of contamination detection for all analyzed milk samples were matched together, a significant difference $(\mathrm{P} 1=0.056)$ was recognized amongst the chosen three cities. Although, Cyhalothrin residues were equally recognized in $17.33 \%$ of milk samples related to Alexandria and El- Behera cities, the percentage of compatibility with the MRL, as per the European Commission (EC) Regulation No 37/2010 (EU) for Cyhalothrin which is $50 \mathrm{ppb}$, showed quite change. Accordingly, there were 2.66 and $1.33 \%$ of Cyhalothrin-contained milk samples from Alexandrian and El- Behera exceeded the MRL. By analyzing the frequencies of Cyhalothrin detection, all the mean contamination values were settled above the median levels for contaminated samples. Consequently, the mean values \pm (standard deviations) $>$ median levels $(\mathrm{Q} 1-\mathrm{Q} 3)$ were as follows: $26.88 \pm(15.97)>21.34(15.76-36.07)$ and $27.18 \pm$ $(15.81)>20.62(16.22$ - 35.02) for Alexandria and El- Behera- contaminated samples, respectively. Despite the percentage of contaminated milk samples related to Matrouh city was somewhat high (28\%), none of them went beyond the MRL of the (EC) Regulation No 37/2010, while the mean value \pm (standard deviations) > median level (Q1-Q3) were $16.18 \pm(4.13)>13.96(13.25-18.07)$, respectively.

Finally, there was insignificant difference $(\mathrm{P} 2=0.783)$ in the percentages of frequency detection levels among contaminated samples. Deltamethrin residues were noticed at the highest mean level among El- Behera- collected milk samples when compared with the other selected cities where mean level \pm (standard deviations) was $3.05 \pm(7.84)$ ppb, followed by Matrouh then Alexandria- collected milk samples in which the values were $2.69 \pm(6.08)$ and 2.45 $\pm(6.68)$ $\mathrm{ppb}$ of whole milk, respectively. All examined milk samples among the three cities were significantly different $(\mathrm{P} 1=$ 0.112) based on the contamination detection levels. Concerning the frequency percentages of Deltamethrin detection amongst contaminated milk samples, there were 14.66, 16 and $24 \%$ of collected samples from Alexandria, El- Behera and Matrouh cities were contaminated, respectively. Furthermore, when the contaminated samples compared with MRL of CAC (2018) which is $30 \mathrm{ppb}$ for Deltamethrin, the percentages of incompatible samples were 1.33 and $2 \%$ for Alexandria and Matrouh cities, while, the highest percent of contaminated samples was related to El- Behera city which was $4 \%$. The data of frequency detection levels revealed a significantly difference $(\mathrm{P} 2=0.502)$ between contaminated samples. Regarding the variability in the frequencies of Deltamethrin detection among contaminated milk samples, the arithmetic means \pm (standard deviations) were in this order: $18.83 \pm(9.18)>16.83 \pm(7.22)>16.31 \pm(8.53)$ for ElBehera > Matrough > Alexandria- contaminated milk samples. Subsequently, robust medians with interquartile ranges (Q1-Q3) reached 13.95 (11.14 - 17.53), 14.80 (12.40 - 25.57) and 15.41 (13.16 - 17.64) in Alexandria, El- Behera and Matrouh- contaminated milk samples, respectively.

\section{DISCUSSION}

Diverse pesticides could get entrance into milk and dairy products via presence of their residues in dairy animal feed stuffs and or improper application on farm animals, environmental pollution and unintentional falls. Therefore, inhibiting the potential sources of contamination is the first step for milk protection system against the pesticides residues. Recently, synthetic pyrethroids are commonly used due to their prohibited rule against many types of pests in farms, mammals and public health commitments Gao et al. (2013). In this study of the pyrethroid residues in raw bovine milk, Cypermethrin was the prevalent pyrethroid with the highest occurrence of positive marks being existing in milk samples collected from local producers in West Delta region of Egypt, followed by Cyhalothrin and then Deltamethrin residues. In addition, the highest percentage of contaminated samples by Cypermethrin residues as well as the mean values, ppb \pm (standard deviations) were related to Matrouh city (44\% and $10.74 \mathrm{ppb} \pm$ (20.79) when matched with Alexandria (18.66\% and $6.63 \mathrm{ppb} \pm$ (16.54) and El- Behera (21.33\% and $5.98 \mathrm{ppb} \pm(15.05)$, in turn this specifies its frequent use to control the pests on a wide scale in different areas of Matrouh. This result is in strong agreement with Muhammad et al. (2012) who found the highest concentration level of Cypermethrin in milk than rest of the inspected pyrethroids in Pakistan. In addition, these mean levels are higher than those reported by Hassan et al. (2014) in Pakistan and Ismail and Elkassas (2016) in Egypt in which the mean concentrations of Cypermethrin in raw milk were 0.23 and 0.1985 ppm while, the frequencies were 21 and 13\%, respectively. On the other hand, the frequency of Cypermethrin detection measured in present investigation was lower than that reported in a study conducted in Brazil by Dallegrave et al. (2018), in which the frequency of Cypermethrin in raw milk reached $92 \%$ but mean concentration was 2.75 ppm which is lower than the value of the present study. Furthermore, the present result was higher than that of Goulart et al. (2008) who found the concentration level of $0.75 \mathrm{ppm}$ for Cypermethrin in raw milk. On the contrary, there was a study in South Africa conducted by Sereda et al. (2009) with no detection levels for any Cypermethrin residues in bovine milk. All samples showed concentrations lower than the MRL established by CAC (2018) for Cypermethrin: 100ppb and this data is in the same line with Bedi et al. (2018) in India and Dallegrave et al. (2018) in Brazil. Present result was nearby those reported by Bedi et al. (2015) who found $99 \%$ of analyzed milk samples in India were complied with MRLs for Cypermethrin except one sample but with lower mean concentration (ppb) and frequency \% which were $0.9 \pm 5.0 \mathrm{ppb}$ and $4.1 \%$, respectively. This incidence might constitute a public health hazard due to presence of $\alpha$ - cyano group in the structure of Cypermethrin as one of type II pyrethroids which produces a toxigenic impact especially on liver and kidneys in addition to the stimulation of genetic damage on a long-term exposure (Vardavas et al., 2016). 
In the current study, the concentration and frequency levels for Cypermethrin residues were found at high abundancy. This can be attributed to its rapid solubility with high capability to form covalent bonds with some milk proteins, thus predominates in the milk (Gao et al., 2010). In Egypt, people especially farmers widely use Cypermethrin as agricultural and anti-parasitic pesticide to counteract external parasites of animals such as ticks. This fact may be an explanation for its incidence of $44 \%$ in Matrouh- contaminated milk samples. Being toxic to marine and aquatic organisms, Cypermethrin, is included in the list of restricted pesticides by EPA, however in Egypt, it is widely assimilated to prevent a broad range of pests in agronomy and veterinary divisions. Also, it is used to control the pests at home and buildings. Therefore, the high concentration levels of Cypermethrin may constitute adverse health impressions. As regards the Cyhalothrin and Deltamethrin mean values of detection level among examined milk samples, the highest mean values were associated with El- Behera city when compared with other cities in which mean values, $\mathrm{ppb} \pm$ (standard deviations) were $5.14 \mathrm{ppb} \pm$ (12.62) and $3.05 \mathrm{ppb} \pm$ (7.84) for Cyhalothrin and Deltamethrincontained samples, consequently. However, the highest percentages of contaminated samples were reported in Matrouh city with $28 \%$ and $24 \%$ for Cyhalothrin and Deltamethrin- contaminated milk samples, respectively. The results of detection levels for Cyhalothrin and Deltamethrin residues in this study were higher than those reported by Dallegrave et al. (2018) who reported the mean concentration values of Cyhalothrin and Deltamethrin in Brazilian raw milk of 0.28 and $0.20 \mathrm{ppm}$, respectively but with higher frequencies than the present result (76 for Cyhalothrin and $13 \%$ for Deltamethrin). The mean residue level and frequency of Deltamethrin in the current study were high in comparison with Hassan et al. (2014) where the mean amount was $0.21 \mathrm{ppm}$ and frequency was only $7 \%$ for analyzed milk samples in Pakistan. Similarly, Bedi et al. (2015) reported lower mean (ppb) and frequency (\%) levels which were $0.8 \pm 4.3 \mathrm{ppb}$ and $4.5 \%$ for Cyhalothrin while for Deltamethrin were $0.5 \pm 3.4 \mathrm{ppb}$ and $2.2 \%$, respectively.

Consequently, in the current study, Deltamethrin residues showed the least mean concentration levels within other pyrethroid pesticides in the examined milk samples. This could be attributed to its low persistence, therefore diminish quickly in milk. The similar findings were reported by Ahmad et al. (2012) in Pakistan and Dallegrave et al. (2018) in Brazil Notwithstanding, Deltamethrin is identified less frequently than Cypermthrin, however the toxigenic effect of Deltamethrin may be more dangerous than Cypermethtrin as confirmed by Shen et al. (2012). On the contrary, some Egyptian authors failed to detect Deltamethrin in any examined raw milk samples for example, Nasr et al. (2007) in Gharbia City and similarly, Ismail and Elkassas (2016) in Kafr El-sheikh City due to the restricted usage of this pesticide. The present results for Cyhalothrin and Deltamethrin are in the contrary with the Indian study by Bedi et al. (2018) who found all milk samples were free from both residues. Moreover, about 2.66 and $1.33 \%$ of Alexandria and ElBehera- contaminated milk samples, respectively were above the MRL of European Commission (EC) Regulation No 37/2010 Cyhalothrin: 50 ppb. Concerning the MRL of CAC (2018), for Deltamethrin which is 30 ppb, there were $1.33,4$ and $2 \%$ of Alexandria, El- Behera and Matrouh- contaminated milk samples, respectively exceeded the MRL. There were significant differences in the detection levels of examined pyrethroid residues in all milk samples among selected cities as well as among frequencies of detection except for Cyhalothrin frequency percentages among contaminated milk samples which was (P2=0.783).

Usually, pyrethroid which possesses trans conformation are hydrolyzed more readily by mammalian esterases with reduced toxicity than those with the cis conformation like Deltamethrin. Although presence of Deltamethrin residues in milk may constitute a great public health hazard, it could be rapidly absorbed and this proved in a study performed by Castillo et al. (2013) who found a very low level of Deltamethrin residues in milk $(<1 \%)$ after their initial application, and maximum levels were achieved in milk after 2 days with undetectable residue level in milk after 8 days of treatment. In Egypt, the bad habit of consuming raw milk directly after milking can be done by some people especially farmers which in turn can lead to conceivable adverse health impacts. Additionally, pesticide containers might be left nearby or even in the same area of milking places that may lead to unintentional leakage and milk pollution. Furthermore, application of pyrethroid sprays on crops neighboring to dairy housing may result in spreading and accumulating of their aerosols on dairy animal premises, water and foods which finally causing milk to be contaminated. Finally, feeding of dairy animals on pyrethroids- polluted crops can cause their residual descending in milk. So, great attentions should be implemented about proper raw milk handling and processing, protection against exposure via feed or from animal environment in addition to continual monitoring the withdrawal time of pyrethroid residues in milk which is very crucial to protect the public health and assess the food safety. Therefore, the recognition of synthetic pyrethroid residues is the head point in relations of preventive actions for ensuring food safety and public health. Every year, programs are held by EU to display and prevent objectionable contamination of foods and raw materials to safeguard consumers.

\section{CONCLUSION}

Presence of pyrethroid residues in evaluated milk samples signposts either the use of these pesticides in the past or their continual application till now in many fields such as agricultural and medical purposes. Contamination of such milk samples with pesticides may constitute a noticeable hazard to Egyptian consumers particularly in Matrouh which was the 
most contaminated city with examined pyrethroid residues owing to the haphazard use of pesticides on growing crops with the lack of notification about corrective application regimens. Additionally, the grazing habit of dairy animals especially in Matrouh which feed on growing crops. Although the pyrethroids are detected in possible quantities but the unlimited increase of these residues may cause harmful impacts on human health. Additionally, concentration level of some pyrethroids went beyond to (MRL) in a number of milk samples which is also an issue of worries about consumer health. Therefore, monitoring strategies should be continually applied to ensure pesticide residues level in milk as well as in the areas where enormous quantity of pesticides are applied every year without scheduled monitoring for to achieving the safety of consumer health and ensuring the food safety criteria in country.

\section{DECLARATION}

\section{Authors' contributions}

Amer Abd El-Moamen Amr designed the study, conceptualized, conducted the practical part of research, prepared the final draft, performed the statistical analysis of the obtained data. Abou-Alella Abd-Elmohsen Sarah visualized and investigated the experiments, interpreted the results, collected the research papers, collaborated in writing of the final manuscript. All authors checked the submitted manuscript and approved it for publication present journal.

\section{Competing interests}

The authors declare that they have no conflict of interest

\section{Acknowledgments}

The authors are grateful to the stuff members of Food Hygiene and Control Department, Faculty of Veterinary Medicine, Alexandria University for their financial support and academic help to complete this work.

\section{REFERENCES}

Ahmad L, Khan A and Khan MZ (2012). Pyrethroid induced reproductive toxico-pathology in non-target species. Pakistan Veterinary Journal, 32 : 1-9. Available at: www.pvj.com.pk.

Association of Official Analytical Chemists (AOAC) (1996) Official Methods of Association Official of Analytical Chemists for determination of pesticide residues. $12^{\text {th }}$ Edition. Washington D.C. p. 518.

Bedi JS, Gill JPS, Kaur P and Aulakh RS (2015). Pesticide Residues in Bovine Milk in Punjab, India: SpatialVariation and Risk Assessment to Human Health. Archives of Environmental Contamination and Toxicology, 69: 230-240. DOI:https://www.doi.org/10.1007/s00244-015-0163-6.

Bedi JS, Gill JPS, Kaur P and Aulakh RS (2018). Pesticide residues in milk and their relationship with pesticide contamination of feed stuffs supplied to dairy cattle in Punjab (India). Journal of Animal and Feed Sciences, 27: 18-25. DOI:https://www.doi.org/10.22358/jafs/82623/2018.

Bissacot DZ and Vassilieff I (1997). Pyrethroids residues in milk and blood of dairy bovines following single topical applications. Veterinary and Human Toxicology, 39 (1): 6-8. Available at: https://www.ncbi.nlm.nih.gov/pubmed/9004471.

Bordoni L, Nasuti C, Fedeli D, Galeazzi R, Laudadio E, Massaccesi L, López-Rodas G and Gabbianelli R (2019). Early impairment of epigenetic pattern in neurodegeneration: additional mechanisms behind pyrethroid toxicity. Experimental Gerontology Journal, 124 : 110629. DOI:https://www.doi.org/10.1016/j.exger.2019.06.002.

Castillo AR, St-Pierre NR, Silva N and Weiss WP (2013). Mineral concentrations in diets, water, and milk and their value in estimating on-farm excretion of manure minerals in lactating dairy bovines. Journal of Dairy Science, 96: 3388-3398. DOI: https://www.doi.org/10.3168/jds.20126121.

Codex Alimentarius Commission (CAC) (2018). Codex Online Database Pesticides Residues in Food. Available at: http://www.fao.org/faowhocodexalimentarius/codex-texts/dbs/pestres/commodities-detail/en/?lang=en\&c_id=187.

Corcellas C, Eljarrat E and Barceló D (2014). Enantiomeric-selective determination of pyrethroids: application to human samples. Analytical and Bioanalytical Chemistry, 407(3): 779-786. DOI: https://www.doi.org/10.1007/s00216-014-7905-6.

Dallegrave A, Pizzolato TM, Barreto F, Bica VC, Eljarrat E and Barceló Damià (2018). Residue of insecticides in foodstuff and dietary exposure assessment of Brazilian citizens, Food and Chemical Toxicology, 115: 329-335. DOI:https://www.doi.org/10.1016/j.fct.2018.03.028.

European Commission. (2010). Commission Regulation (EU) No. 37/2010 of 22 December 2009 on pharmacologically active substances and their classification regarding maximum residue limits in foodstuffs of animal origin. Official Journal of the European Union, L15:1-72. Available at: http://data.europa.eu/eli/reg/2010/37(1)/oj.

Feo ML, Eljarrat E, Barceló D and Barceló D (2010). Determination of pyrethroid insecticides in environmental samples. TrAC Trends in Analytical Chemistry, 29 (7): 692-705. DOI: https://www.doi.org/10.1016/j.trac.2010.03.011.

Gammon DW, Liu Z, Chandrasekaran A, El-Naggar SF, Kuryshev YA and Jackson S (2019). Pyrethroid neurotoxicity studies with bifenthrin indicate a mixed Type I/II mode of action. Pest Management Science, 75 (4): 1190-1197. DOI: https:// www.doi.org/10.1002/ps.5300.

Gao XS, ZhangY, Wang SX, Hua R and Zhang XM (2010). Determination of pyrethroid pesticide residues in milk by QuEChERS-gas chromatography. China Dairy Cattle, 8: 56-60. DOI: https://www.doi.org/10.3969/j.issn.1004-4264.2010.08.020.

Gao Y, Sun Y, Jiang C, Yu X, Wang Y, Zhang H and Song D (2013). Fast determination of pyrethroid pesticides in tobacco by GC-MS-SIM coupled with modified QuEChERS sample preparation procedure. Analytical Sciences, 29 (6): 649-653. DOI: https://www.doi.org/10.2116/analsci.29.649.

Gong DC (2013). Pyrethroids pesticides residues and their behavior in a multimedium Environment of Liangtan River Basin [Master thesis]. Chongqing: Chongqing Univ.

Goulart SM, de Queiroz MELR, Neves AA and de Queiroz JH (2008). Low-temperature clean-up method for the determination of pyrethroids in milk using gas chromatography with electron capture detection. Talanta, 75 (5): 1320-1323. DOI: https://www.doi.org/10.1016/j.talanta.2008.01.058. 
Hassan AU, Tabinda AB, Abbas M and Khan AM (2014). Organochlorine and Pyrethroid Pesticides Analysis in Dairy Milk Samples Collected from Cotton Growing Belt of Punjab, Pakistan. Pakistan Journal Agricultural Sciences, 51 (2): 321-325. Available at: http://www.pakjas.com.pk.

Hudson NL, Kasner EJ, Beckman J, Mehler L, Schwartz A, Higgins S, Bonnar-Prado J, Lackovic M, Mulay P, Mitchell Y et al. (2014). Characteristics and magnitude of acute pesticide-related illnesses and injuries associated with pyrethrin and pyrethroid exposures-11 states, $2000-2008$. American Journal of Industrial Medicine, 57(1): 15-30. DOI: https:// www.doi.org/10.1002/ajim.22216.

International agency for research on cancer (IARC) (2014). IARC Monographs on the Identification of Carcinogenic Hazards to Humans. Available at: https://monographs.iarc.fr/ENG/Publications/internrep/14-002.pdf. (Accessed on 21 October 2016).

Ismail T and Elkassas WM (2016). Prevalence of Some Pesticides Residues in Buffalo's Milk with Refer to Impact of Heating. Alexandria Journal of Veterinary Sciences, 48 (2): 113-123. DOI: https://www.doi.org/10.5455/ajvs.215565.

Kampire E, Kiremire BT, Nyanzi SA and Kishimba M (2011). Organochlorine pesticide in fresh and pasteurized bovine's milk from Kampala markets. Chemosphere, 84 (7): 923- 927. DOI: https://www.doi.org/10.1016/j.chemosphere.2011.06.011.

Muhammad F, Javed I, Akhter M, Rahman Z, Awais, MM, Saleemi MK and Anwar MI (2012). Quantitative Structure activity relationship and risk analysis of some pesticides in the cattle milk. Pakistan Veterinary Journal, 32 (4): 589-592. Available at: www.pvj.com.pk.

Nasr IN, Sallam AAA and Abd El-Khair AA (2007). Monitoring of certain pesticide residues and some heavy metals in fresh bovine's milk at Gharbia City, Egypt. Journal of Applied Science, 7 (20): 3038-3044. DOI: https://www.doi.org/10.3923/jas.2007.3038.3044.

Panseri S, Vigo D, Chiesa LM, Biondi PA and Communod R (2013). Occurrence of organochlorine pesticides residues in animal feed and fatty bovine tissue: Chapter 13. Food Industry, In: D. Paradis, G. Berail, J. M. Bonmatin, L. P. Belzunces (editors), Sensitive analytical methods for 22 relevant insecticides of 3 chemical families in honey by GC-MS/MS and LC-MS/MS. Analytical and Bioanalytical Chemistry, 406: 621-633. DOI: https://www.doi.org/10.5772/54182.

Sereda B, Bouwman H and Kylin H (2009). Comparing Water, Bovine Milk, and Indoor Residual Spraying as Possible Sources of DDTand Pyrethroid Residues in Breast Milk, Journal of Toxicology and Environmental Health, Part A: Current Issues, 72: 842-851. DOI: https://www.doi.org/10.1080/15287390902800447.

Shen MF, Kumar A, Ding S and Groke S (2012). Comparative study on the toxicity of pyrethroids, Cypermethrin and Deltramethrin to Ceriodephnia dubia. Ecotoxicology and Environmental Safety, 78: 9-13. DOI: https://www.doi.org/10.1016/j.ecoenv.2011.07.018.

Vardavas AI, Stivaktakis PD, Tzatzarakis MN, Fragkiadaki P, Vasilaki F and Tzardi M et al. (2016). Longterm exposure to cypermethrin and piperonyl butoxide cause liver and kidney inflammation and induce genotoxicity in New Zealand white male rabbits. Food and Chemical Toxicology, 94: 250-259. DOI: https://www.doi.org/10.1016/j.fct.2016.06.016.

World Health Organization. WHO (1989). Cypermethrin Environment. Health Criteria. 82: 1-154. Available at: http://www.who.int/whopes/quality/en/.

Wu C, Feng C, Qi X, Wang G, Zheng M, Chang X and Zhou Z (2013). Urinary metabolite levels of pyrethroid insecticides in infants living in an agricultural area of the province of jiangsu in china. Chemosphere, 90 (11): 2705-2713. DOI: https://www.doi.org/10.1016/j.chemosphere.2012.11.050.

Wu Y, Miao H and Fan S (2011). Separation of Chiral Pyrethroid Pesticides and Application in Pharmacokinetics Research and Human Exposure Assessment: Chapter 8. In: M. Stoytcheva (Editor), Pesticides in the Modern World - Effects of Pesticides Exposure, pp. 139-166. DOI: https://www.doi.org/10.5772/16617.

Yu X, Ang HC, Yang HS, Zheng C and Zhang YQ (2017). Low temperature cleanup combined with magnetic nanoparticle extraction to determine pyrethroids residue in vegetables oils. Food Control, 74: 112-120. DOI: https://www.doi.org/10.1016/j.foodcont.2016.11.036. 